\title{
Literary Imagination of Construction of Community With a Shared Future in Alice Munro's Stories
}

\author{
Haixia Zhang \\ School of Liberal Arts, Ningxia Normal University, Guyuan, Ningxia, 756000, China \\ Email: 640382952@qq.com
}

\begin{abstract}
Alice Munro has made a great contribution to Canadian literary history because of her writing about her own town and nation in a style of realism and the achievements she has gotten in short-story writing. Under her pen, the life of the city, community and family is full of stress and tension in a piece-looking way. The meaningful narration underlying her story embodies ecological color to novels. This article draws many writings of Munro's stories and analyzes the meaning of space writing, body writing, scenery writing and relations writing. Heroine living environment in the works and their relationship with men and nature. The various types of writing shows writer's ecological writing consciousness, expands stories' deep connotation. In this sense, Alice Munro's novels provide significant thoughts about construction of a community with a shared future by stories' literary imagination.
\end{abstract}

Keywords: Alice Munro, Ecological writing, Literary imagination, Community with a shared future

\section{INTRODUCTION}

As one of the most famous contemporary short story writers in Canada, Alice Munro has made a great contribution to Canadian literary history because of her writing about her own town and nation in a style of realism and the achievements she has gotten in short-story writing. Meanwhile, as the $13^{\text {th }}$ winner in the Nobel Prize for literature in 2013, she will be the pride for the nation of Canada and the treasure for the readers all over the world undoubtedly. Munro is such a plentiful writer that you could not complete to read all her novels in some short time even if you are a reader loves her stories so much. She is fond of writing the routine life and environment of a small town in south Canada where is the location of her hometown. Under her pen, the life of the city, community and family is full of stress and tension in a piece-looking way. This always leaves readers aftertaste and thinking.

\section{MUNRO'S VARIOUS TYPES OF LITERARY WRITING}

Undoubtedly, Munro has not only great talent in writing stories, but also has strong interest in every detail and aspect in her life. As we all know that she has wrote hundreds of stories. There are many different types of events contained in her pen. Although ordinary, they are of deep and unusual meaning. The depth of stories' connotation was often extended by those various types of writing.

\subsection{Space Writing}

Space can be a material exist we live by and also can be a spiritual realm we communicate with in an invisible form. As the society develops, the problems associated with space are more and more serious for modern people no matter where they live. Alice Munro focuses on both physical space and psychological space we face in our daily life by stories. In Floating Bridge, she creates an image of cemetery opposite to the hospital which heroine usually goes to see doctor quietly. Jinny has got cancer, so she needs to go the hospital termly. Whenever she goes or passes by there, she will think of death. Cemetery and hospital are the two physical spaces, which respectively matters death and living. Also at the beginning of the story, Jinny's psychology was reflected by the space of bus station and her home. She fled from home with upset mood, came to the station with confusion and saw the graffiti wall. There is a strong contrast in the open space the station stands and the enclosed space her home stands. By such description, the meaning of free gradually appears. There are a strong sense of tension between those spaces. As pairs of opposite strength, they make Jinny depressive extremely. That is, Jinny's enclosed life space made her long for free. We can read that there will always be a relevance between space in the sense of specification and abstraction. Through the description of Munro's stories, readers could get an strong feeling about the urgency of protecting and building the space both with the beauty in appearance and spirit. 


\subsection{Body Writing}

Story is associated with people and their life closely. The body of people as well as animals in their life are presented by Munro in exquisite narration. Specifically, she pays subtle observation to their organs, looks, appearance, figure, costume and so on. There are fat men, women or cats who have good tastes of food. There figure show they deserves those plentiful food. Some women pay special attention to there clothing but others don't, such as Catherine and Stella in Lichen. Besides, there are many people have something wrong with there eyes, such as the dad, the girl friend and the cat in Lichen.

Body writing can be seen everywhere in Alice Munro's stories. Actually, it refers to much more meaning than we got at first glance. Take Lichen as an example. The writer tells a story took place at Stella's home. She had lived apart with here husband for a long time. The latter paid a visit to her with his new girlfriend one day. David express a strong sense of dissatisfaction with the baggy clothing of his wife before his girlfriend with delicate skirt. Stella doubt that there was something wrong with Catherine's eyes. In the process of reading, we know her father and cat were just with one eye. First, each element connected with body refers to the first impression it presents to others, for example, beautiful or ugly, charming or disgusting, healthy or not... Second, the impression getting from others' eyes includes their judgement, aesthetic standard and desire for the owner of the body. In this sense, the looker will pose their power to people who was looked. Here, body is a place where others can exercise their right on them[1].

\subsection{Scenery Writing}

Whatever the scenery is natural or cultural, it has their indispensable position in Munro's stories. In the story What Do You Want to Know For? which is in the collection named The View from Castle Rock, ice was drew as natural scenery. "A glacial landscape such as this is vulnerable.[2]" Between its stage of conquests and retreats, perhaps there was the ecological issue hidden under the lines. "Bermingham regards landscape as an ideological 'class view' to which; the painted image gives 'cultural expression." [3]. therefore, when concerning about nature and ecology, it relates to men's powerful activities to harm them. Critical attitude are always expressed in an artistic way. Cultural scenery is overall. They can be buildings, advertising board and so on. "we had the excitement of the trucks going past all day, as well as the importance of the sign at our gate. Children Playing.[2]" The "sign" here which made children exciting conveys a sense of being or subjectivity, by which playing children get an sense of importance from busy adult world. Besides, the description about remote place in town in many stories of Alice Munro maybe bear some special meaning about one's attachment to the family, the attraction and power on them coming from the center of city. Scenery is endowed delicate sense to reveal stories connotation with many other elements.

\subsection{Relations Writing}

It seems that Alice Munro is very interested in writing relations between parents and their children, men and women, husbands and their wives and friends each other. Each relationship bears meaning out of ordinary. The stories The Progress of Love, Floating Bridge and The Bear Came Over the Mountain are some of the most typical works to reveal and explore husband-wife relation. The serious fact is that there are many disharmonious elements existing in the relations, such as depression, anxiety, tension, indifference and so on. Take The progress of Love as an example. The father in that story phoned his child to tell the death of his own wife-his child's mother. From father's tone with a kind of calm, protagonist even felt a sort of ease with his father's mood from mother's death in a very unnoticed and secret way. Readers may feel pity for the mother, but perhaps the father's spiritual world needs to be explore to understand his marital status. In Dimensions, Doree's husband Lloyd once was an orderly who was "popular with the patients because of his jokes and his sure, strong touch"[4]. one day, they quarreled with each other because of the safety of children's food. Doree left home to friend's home with anger and didn't came back that night. However, when she came back the next day, she found their children's death. Although parents-hood was not the main theme of this story, but in fact, what on earth is the beloved and reasonable kind of idea for parents who wanted to build a good relationship with children and educate them well is such a important question needed to be thought deeply. There always be conversion between to love and to harm. Mrs.Cross and Mrs. Kidd and Runaway are the two stories with the theme of friends' relations of the same sex. However, the former is friends who are seemingly in harmony but actually at variance, the later are friends who appreciate, help and encourage each other to be a nicer self. Such presentation of relations draw readers attention to have a clear understanding about the reason and the fact: why did the relationship unsatisfied man and how important to build a sincere, healthy and conversational relationship with others.

\section{LITERARY CONSTRUCTION OF COMMUNITY WITH A SHARED FUTURE}

Alice Munro always tells her stories in a very calm and realistic attitude. She really deserves the appraise that she is the most influential contemporary short story writer. Novels of Alice Munro's tries her hard to present the beings of nature, the changes in society, the spirit of scenery and the subtle and complicated between people by telling a large number of life stories. As a sort of literary imagination, they reveal an important fact needs to be noticed eagerly and wildly that the disharmony surrounding us is derived from the idea of power and anthropocentrism. Therefore, her novels are of a flow of ecological realization. Her ecological thought about the relationship between man and woman, 
human and nature is the key to enter into her novels' connotation.

\subsection{Ecological Imagination in Alice Munro's novels}

Ecological consciousness is an theoretical idea emphasizes the organic wholeness between human and nature. Even the eco-feminists express their attitude about ecological problem in a more radical way. They think that the male culture treats women and land with indifference. In this way, they are harm to human and nature. "Women need to protect themselves and protect land. There has been alway close relationship between women and nature."[5] Feminists interpret their ecological opinions in a theoretical way, but Alice Munro explores the ecology theme in the literary imagination. She has draw many different relations between women and nature, men and nature, women and society, men and society, and women and man. As it is said, "many women worked in the field without harm to ecological system in the past and such labour way can still be seen occasionally today"[5]. Similarly, women and the nature are hurt by man with protection or indifference in Munro's stories, but women always devote their labour to nature in a harmless way which shows their great concern and care about nature. The desires the men pose on others lead to their control of others. Thus, their centralism causes inequality, disharmony and unbalance. In such kind of narration, Alice Munro's writing is of significant ecological thought in her literary imagination.

\subsection{Literary Enlightenment to Construction of the Community With a Shared Future}

In the height of ecological sense, Alice Munro embody a sense of community to her novels. Apparently, she seemed interested in reveal confusion, conflict or soft violence which are regarded as disharmonious strength in a very quiet way. Those elements focus on the patriarchal ideology and human centralism. As the main stream of social culture, they have less connection with the culture of community which states the equal existence of every types of life in order to ensure the value of common experience of human or society[6]. By analyzing the ecological thought flowing in her novels, we can be enlightened the thought about construction of community with a shared future her novels contain. In Munro's novels, not only women and nature were suffering pressure and destroy, but also men were experiencing anxiety and unease. We find the fact that the reason of men's pain has a close relationship with their sense of pressure and failure coming from women's attitude of the great changes and provocative act to their demand to them. Even they always felt upset in front of nature. When discussing the current significance of reading classical literary works, Haoyu expressed his opinion in a thesis. "The idea about community with shared future for mankind is a new milestone of the history of philosophy and the history of human thought and culture. The classical literary works have never given up to think about it.[7]" Obviously, as a classical literary writer, Munro shapes an idea that both we and the nature lives in one world and we share a common future. Because of our common benefit and happiness, we should adhere to the opinion of community with a shared future for mankind.

\section{SUMMARY}

To sum up, from the light of suffering from repression, women and the nature are on the same side, so it is of the same significance in protecting women and the nature. However, it is more and more obvious that men are also suffering an imperceptible stress. Indeed, they felt anxiety about women's changes. Gradually, they have learned to observe women and try to understand them. Because of the open ending Munro has given to her stories, we can imagine the future of the one world that our human and nature share. We could hold an optimistic hope to that future if all people can communicate with each other fully as well as the nature so that all creatures and beings can exist in his or her or its own natural way. In other words, we are respected only when we respect and fully understand others or nature. With the development of globalization, we actually live in the dual sense of community. The one is for the real living location of us, the other is for the future we share. Without communication and understanding, there were no common sense and multilateral benefit. As an excellent novelist, Alice Munro provides her ecological vision for human society in a vivid and concise literary way.

\section{ACKNOWLEDGEMENT}

This paper was the outcome of the research, Study on Ecological writing of Alice Munro's Novels in the Context of Community with a Shared Future, which was supported by the Foundation for Scientific Research Project of Ningxia Institutions of Higher Education. The project number was NGY2018-131.

\section{REFERENCES}

[1] Sara Mills. (2017) Michel Foucault. Chongqing University Press, Chongqing.

[2] Alice Munro. (2007) The View from Castle Rock. Random House UK, New York.

[3] W.J.T. Mitchell, (2002) Landscape and Power, The university of Chicago Press, Chicago.

[4] Alice Munro, (2014) Family Furnishings: Selected 
Stories, 1995-2014, Alfred A. Knopf, New York.

[5] Greta Gaard; Patrick D. Murphy, (2013) Ecofeminist Literary Criticism: Theory, Interpretation, Pedagogy, China Social Sciences Press, Beijing.

[6] Raymond Williams, (2011) Culture and Society, Beijing, Jilin Press, Beijing.

[7] Y Hao. (2018) How can literature contribute community with shared future for mankind_-also discuss current significance of reading classical literary works. Masterpieces Review, 19:5-10. 